\title{
QUINTUS FABIUS ARISIM. UN COMERCIANTE DE ORIGEN PÚNICO EN LA BÉTICA
}

\section{QUINTUS FABIUS ARISIM. A MERCHANT OF PUNIC ORIGIN IN BAETICA}

\author{
DANIEL MATEO CORREDOR*
}

Resumen: Presentamos un titulus pictus inédito hallado en un ánfora procedente de la excavación del sector 8 de Villaricos (Almería) y que se encuentra depositada en el Museo de Almería. La propia morfología del ánfora, así como el contexto anfórico en el que se localizó, nos permiten encuadrarla en el tercer cuarto del I a.C. El epígrafe, en muy buen estado de conservación y situado in collo, presenta un trianomina referido a un comerciante romano de origen púnico, lo que nos lleva a resaltar el papel que desempeñaron las oligarquías comerciales púnicas a finales de época tardorrepublicana, al menos dentro de su antigua zona de influencia.

Palabras claves: titulus pictus, ánforas romanas, comercio, Cádiz, Villaricos

\section{INTRODUCCIÓN}

El estudio de los tituli picti constituye una de las principales vías para comprender las estructuras productivas y comerciales que se ocultan detrás del transporte de las ánforas en época romana. No obstante, el corpus de inscripciones pintadas sobre ánforas es bastante limitado debido a las dificultades que presenta su conservación. Por ello, creemos de especial interés

* Departamento de Prehistoria, Arqueología, Historia Antigua, Filología Griega y Latina. Universidad de Alicante. Carretera San Vicente del Raspeig, s/n. 03690-San Vicente del Raspeig (Alicante). Correo-e: daniel.mateo@ua.es.

\begin{abstract}
We present a new titulus pictus in an amphora stored in the Museum of Almería from the archaeological excavation in the $8^{\text {th }}$ sector of Villaricos (Almería). The morphology of the amphora and its context let us date it in the third quarter of the first century B.C. The epigraph, that is well preserved and situated in collo, is a trianomina that belongs to a Roman merchant of Punic origin. This fact let us enlighten the role played by Punic merchant oligarchies at the end of late republican period, at least, inside its ancient area of influence.

Key words: titulus pictus, Roman amphorae, trade, Cádiz, Villaricos
\end{abstract}

presentar un nuevo titulus pictus, en buen estado de conservación, que detectamos durante el estudio de un amplio conjunto anfórico procedente de la excavación del Sector 8 realizada en Villaricos y que se encuentra depositado en el Museo Arqueológico Provincial de Almería.

\section{VILLARICOS. LA EXCAVACIÓN DEL SECTOR 8}

El antiguo asentamiento fenicio y romano de Baria se encuentra en el margen izquierdo de la desembocadura del río Almanzora, territorio de la actual Villaricos (Cuevas de Almanzora, Almería) (fig. 1). 


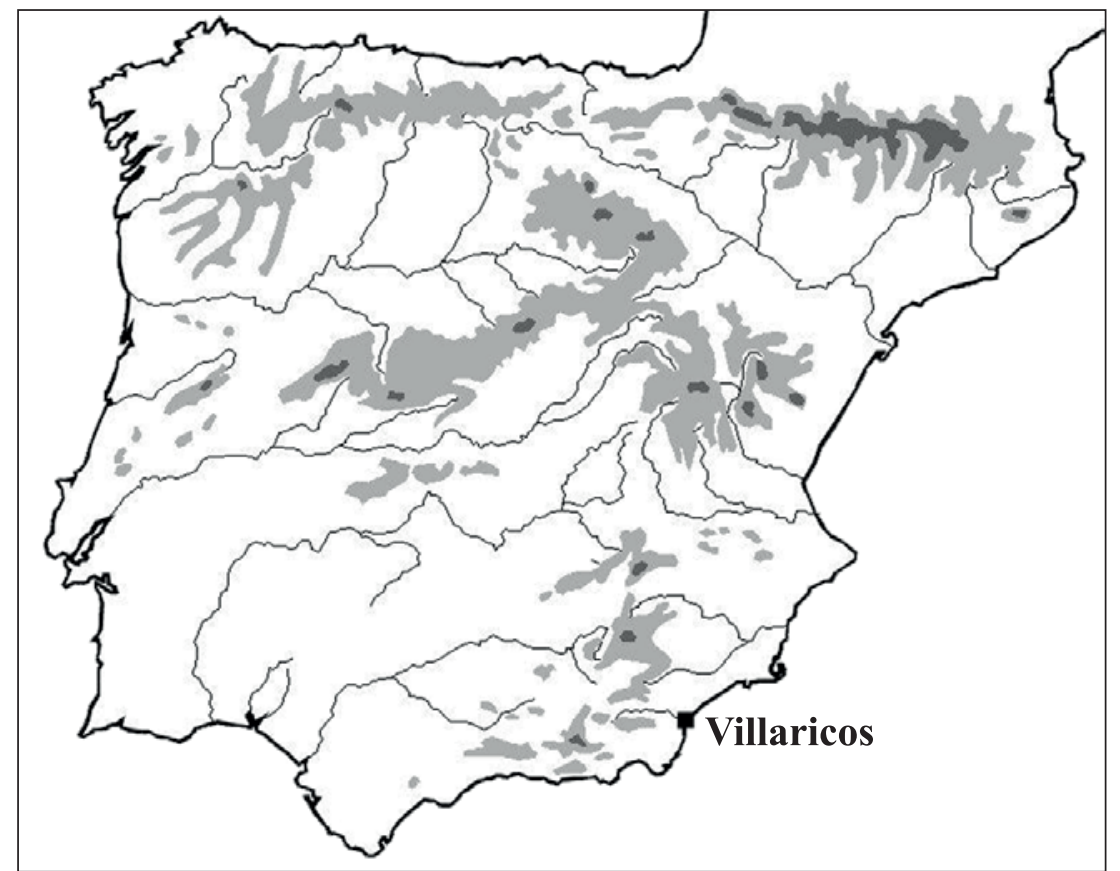

Figura 1. Localización de Villaricos en la Península Ibérica.
Las primeras noticias sobre sus restos se remontan a mediados del siglo XIX (Madoz 1846). Hasta mediados de los 80 las excavaciones realizadas se habían restringido en gran medida a la necrópolis, entre las que destacamos las realizadas por Siret entre 1890 y 1914 (Siret 1906) y por Almagro entre 1975 y 1988 (1984, 1991), que publicó un monográfico sobre el material anfórico (Almagro 1986). Desde entonces, motivado en gran medida por la fuerte presión urbanística, se han llevado a cabo un importante número de excavaciones arqueológicas de urgencia y preventivas (López 2007: 23).

Entre diciembre de 2003 y junio de 2004 se realizó la excavación arqueológica de urgencia del sector 8 , con una extensión de $3.350 \mathrm{~m}^{2}$ y cuyos resultados fueron presentados en unas jornadas monográficas sobre el yacimiento (Morales 2007, Cara 2007). El conjunto excavado presenta diferentes fases de ocupación prácticamente ininterrumpidas desde el siglo VII a.C. hasta el VI d.C. De la fase púnica apenas se hallaron estructuras, siendo ya en época tardorrepublicana cuando se perfila el urbanismo de esta área periurbana, documentándose una zona residencial y las primeras factorías de salazones. Desde inicios del I d.C. se consolida el modelo urbanístico y gran parte del área excavada se incluye dentro de la zona industrial, junto con otras estructuras relacionadas con funciones artesanales y residenciales. En época bajoimperial se registra una contracción en el urbanismo junto con el cese de la actividad salazonera y entre los siglos IV y VI d.C. se produce el abandono de la zona y la ocupación del cercano Cerro de Montroy (Morales 2007: 85).

El ánfora con el epígrafe objeto de este trabajo $\left(\mathrm{n}^{\mathrm{o}}\right.$ de inventario 5343.5) aparece registrada en la UE 2 (sector 3.1) perteneciente al área 5000. La ocupación de esta área arranca en época tardorrepublicana, fase en la que se documentan seis naves rectangulares y cuadrangulares, alineadas de tres en tres. Tras la reparcelación de época altoimperial destaca una nave principal sobre la que se plantea su función como almacén de productos variados (Morales 2007: 60-61).

\section{ANÁLISIS DEL ÁNFORA}

La inscripción se localiza en la parte superior de un ánfora de tipología romana de la que se conserva la boca, el cuello, el inicio del cuerpo y las dos asas. Las ánforas con las que comparte unidad estratigráfica -T-9.1.1.1, Dressel 1A itálica, Lomba do Canho 67 y Ovoide 6/Clase 24-, nos remiten a un contexto cronológico que por sus materiales más modernos datamos en el tercer cuarto del siglo I a.C. (fig. 2).

El ánfora presenta un borde en forma de anillo exvasado con tendencia rectilínea que posee un diámetro de $17 \mathrm{~cm}$ y una altura que oscila entre 3 y $3,7 \mathrm{~cm}$ (fig. 3). El cuello posee forma bitroncocónica bajo el 


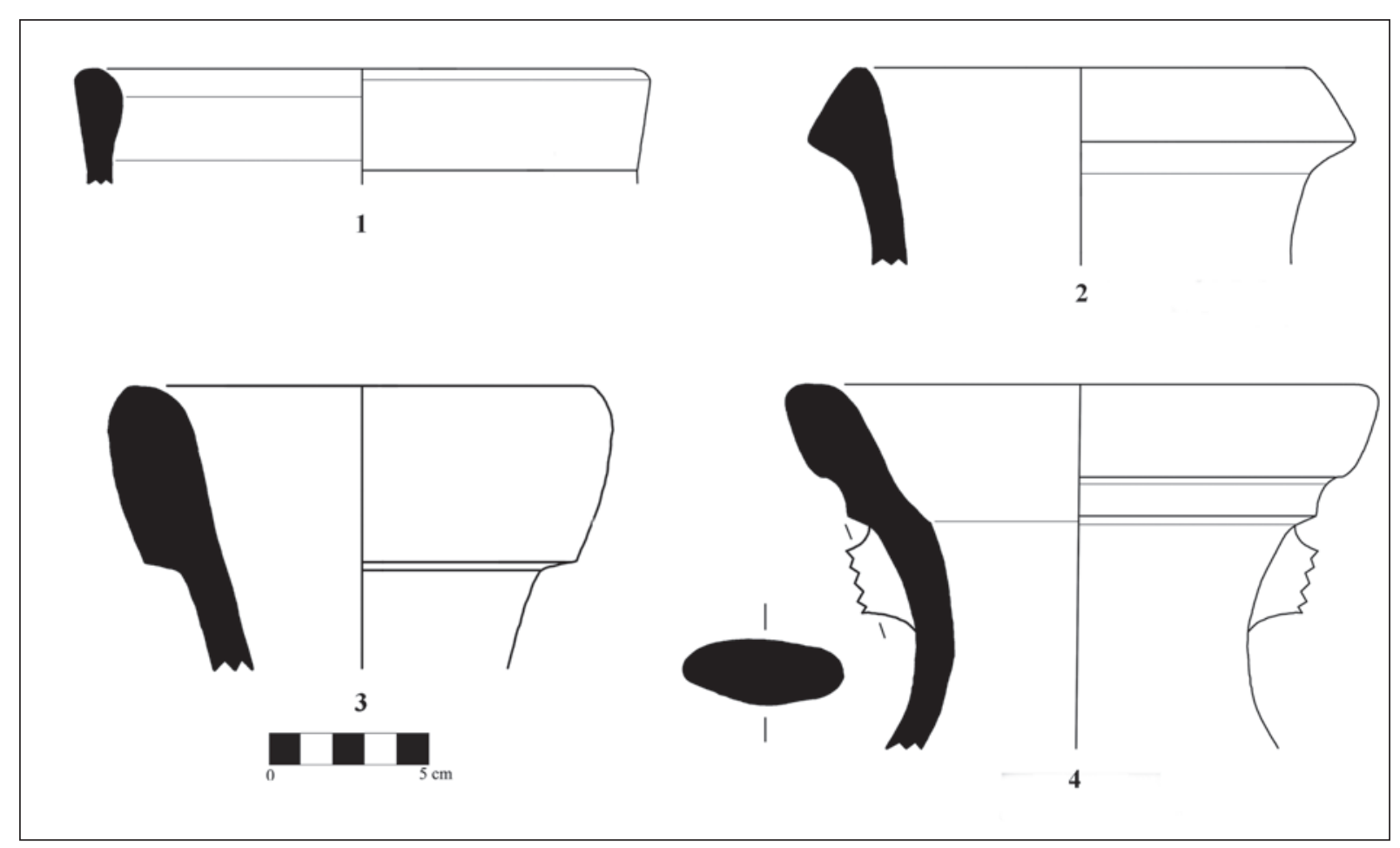

Figura 2. 1. T-9.1.1.1., 2. Dressel 1A, 3. Ovoide 6/Clase 24, 4. Lomba do Canho 67.

cual arranca el cuerpo, que permite intuir una tendencia ovoide. Se conservan también las dos asas, cortas y con perfil semicircular, que parten $2 \mathrm{~cm}$ debajo del borde y descansan sobre unos hombros poco marcados. Las asas presentan una sección elíptica y un ligero surco en la parte central, su diámetro máximo es de $5 \mathrm{~cm}$ y el grosor de $3 \mathrm{~cm}$.

La pasta presenta cocción oxidante, color externo ocre-amarillento, así como un aspecto compacto y duro, de tacto áspero. En su interior posee tonos que oscilan entre marrones anaranjados y marrones claros, las vacuolas son escasas y de pequeño tamaño, y predominan los desgrasantes pequeños y medianos de color blanco y gris, junto a elementos rojizos (hematites). El análisis de lámina delgada (fig. 4) nos muestra la presencia de elementos metamórficos (cuarzos y micas), sedimentarios (carbonatos y cuarzos detríticos) y puntualmente, triásicos de la fase Keüper, así como microfósiles calcáreos. La temperatura de cocción oscilaría entre $\operatorname{los} 850^{\circ} \mathrm{C}$ y $\operatorname{los} 950^{\circ} \mathrm{C}$. Todas las características mencionadas, apuntan a su origen en la bahía de Cádiz, probablemente en la campiña situada al sur del río Guadalete.

Tanto la morfología como el análisis de pastas nos remiten a la familia de las Ovoides gaditanas producidas a finales de época tardorrepublicana y consideradas el origen de las ánforas salsarias béticas altoimperiales (García 1996). La Ovoide gaditana es un tipo todavía no muy bien definido, siendo relativamente escasa la información que poseemos sobre el mismo ante la ausencia en la bahía de Cádiz de excavaciones intensivas de centros de producción datados en los dos primeros tercios del I a.C. (García y Bernal 2008: 679). Presenta una amplia diversidad de bordes y en algunas de sus variantes se puede confundir con las Dressel 9 y 10 -en especial con la variante $\mathrm{C}$ de ésta última-, que derivarían directamente de la Ovoide gaditana (García 1998: 74). Su producción parece iniciarse en torno al 80-70 a.C. tal y como nos demuestra su presencia en el asentamiento minero de La Loba (Benquet y Olmer 2002: 323, fig. 149), y perdurará hasta fechas en torno al 30 a.C., momento en el que se produce su sustitución por las ánforas Dressel 9 y Dressel 10. Este marco cronológico coincide con el de los pecios en los que formaba parte de su cargamento: Titán, Grand Conglué C, Cap Bear, Illes Formigues I y Cala Bona I, (García et al. 2011: 257).

La producción de ánforas de morfología ovoide a partir de los primeros decenios del siglo I a.C. se inserta dentro de una dinámica general que se reproduce 
coetáneamente en el valle del Guadalquivir -donde se da con una mayor diversidad formal- y en otras áreas como Cataluña, Marsella, Marruecos y el litoral portugués. El referente formal del repertorio de las Ovoides tardorrepublicanas parece encontrarse en las producciones brindisinas y se relaciona con el proceso de romanización y de colonización itálica (Fabião 1989, 2001, Molina 2001, Almeida 2008, García et al. 2011), si bien en algunos modelos no puede excluirse la influencia del ánfora Tripolitana Antigua (Mateo 2012: 126).

En relación con el producto envasado, las Ovoides gaditanas, al igual que el resto de ánforas de boca ancha y "exvasada", se han asociado tradicionalmente con el transporte de salazones y salsas de pescado, por lo que creemos que sería el contenido más probable para el ánfora que presentamos. No obstante, no se puede descartar su utilización para el transporte del vino producido en las campiñas gaditanas, pues el hallazgo de restos de uva dentro de dos ovoides gaditanas localizadas en Cádiz (Chic 1980) y en el pecio Grand Congloue 3 (Colls et al. 1977: 89), así como su notable parecido con el tipo Haltern 70 unusually small variant u Ovoide 4 del Guadalquivir, permiten plantear el uso como envase vinario de una de las variantes de este tipo (Étienne y Mayet 2000: 90-91). Este carácter de envase bivalente parece reproducirse igualmente en los tipos que derivan de la Ovoide gaditana de manera más o menos directa-Dressel 9, Dressel 10 y Beltrán 2B-, de los que se han conservado algunos tituli picti que remiten al envasado de vino o derivados de la uva (García 1998, 2004a, García y López 2008).

\section{EL TITULUS PICTUS}

La singularidad de esta ánfora radica en la aparición de un epígrafe pintado en atramentum en el cuello del ánfora (fig. 3). El texto, bien conservado, ofrece una lectura relativamente sencilla:

\section{Q(uintus) FABIUS ARISIM}

La inscripción, elaborada con letras capitales, consta de dos líneas ubicadas en el centro del cuello. La distancia que separa las dos líneas es escasa, entre 0,1 y $0,3 \mathrm{~cm}$ mientras que la altura de las letras se mantiene bastante regular en ambas líneas, oscilando entre 1,10 y 1,40 cm. No apreciamos indicios de que hubiese más inscripciones que se hubiesen perdido o de que el epígrafe continuase en alguno de los extremos. Las características paleográficas de la inscripción no entran en contradicción con la cronología propuesta en el apartado anterior (50-25 a.C.).

El titulus pictus hace referencia a un trianomina cuyo nomen nos acerca a la gens de los Fabii, muy representada en Hispania (Abascal 1994), sobre todo en la Bética (González 1989: 36). Miembros de esta gens desarrollaron una importante vinculación con la provincia hispana. Así, desde la creación de la provincia de Hispania Ulterior fueron varios los gobernadores pertenecientes a esta gens -entre los que destaca Quinto Fabio Maximo Serviliano (143-140 a.C.)-, situación que continuará durante el Alto Imperio, cuando también encontramos asentada en la Bética a una bien conocida rama familiar, los Fabii Fabiani (Canto 1978), que desempeñaron un activo papel en el comercio de aceite bético destinado a la Annona imperial, al igual que los Fabii Iuliani (Chic 2003).

Por el contrario, el cognomen Arisim era hasta ahora desconocido en la Península Ibérica y, fuera de ella, tan sólo lo hemos encontrado en tres inscripciones (AE 2000, 01682; AE 1959, 00172; ILAlg-02-02, 04296), todas procedentes del norte de África, aunque en ninguna de ellas realiza función de cognomen. Muy probablemente este Arisim debe ponerse en relación con la latinización del nombre púnico, 'ř̌m, que para Jongeling (1994) pertenece a la misma familia que Aris, Arinis, Arisi, Arisu y Arionis. Sobre el significado de la terminación -im en las inscripciones latinas africanas, se ha señalado su posible uso para indicar el femenino o el púnico plural, así como una posible relación con el sustrato bereber, pero ninguna de estas interpretaciones parece concluyente (Jongeling 1984: 36; 1994: 22-23). El término Aris lo encontramos con caracteres griegos en una estampilla del ánfora cartaginesa T-7.4.3.1 hallada en Cádiz (Perdigones et al. 1986: fig. 1). La helenización de las grafías de nombres púnicos en epigrafía anfórica (Ramón 1995: 248-251) no es una novedad en la Península Ibérica donde esta situación también la encontramos para el sello MAГON (Aranegui 2002, Molina 2007: 210).

Así pues, siguiendo la conocida práctica de romanización del nombre, se trataría de un indígena que al adquirir la ciudadanía romana conservaría su nombre púnico como cognomen, tomando como praenomen y nomen el de algún notable romano, a cuya clientela podría pertenecer. 


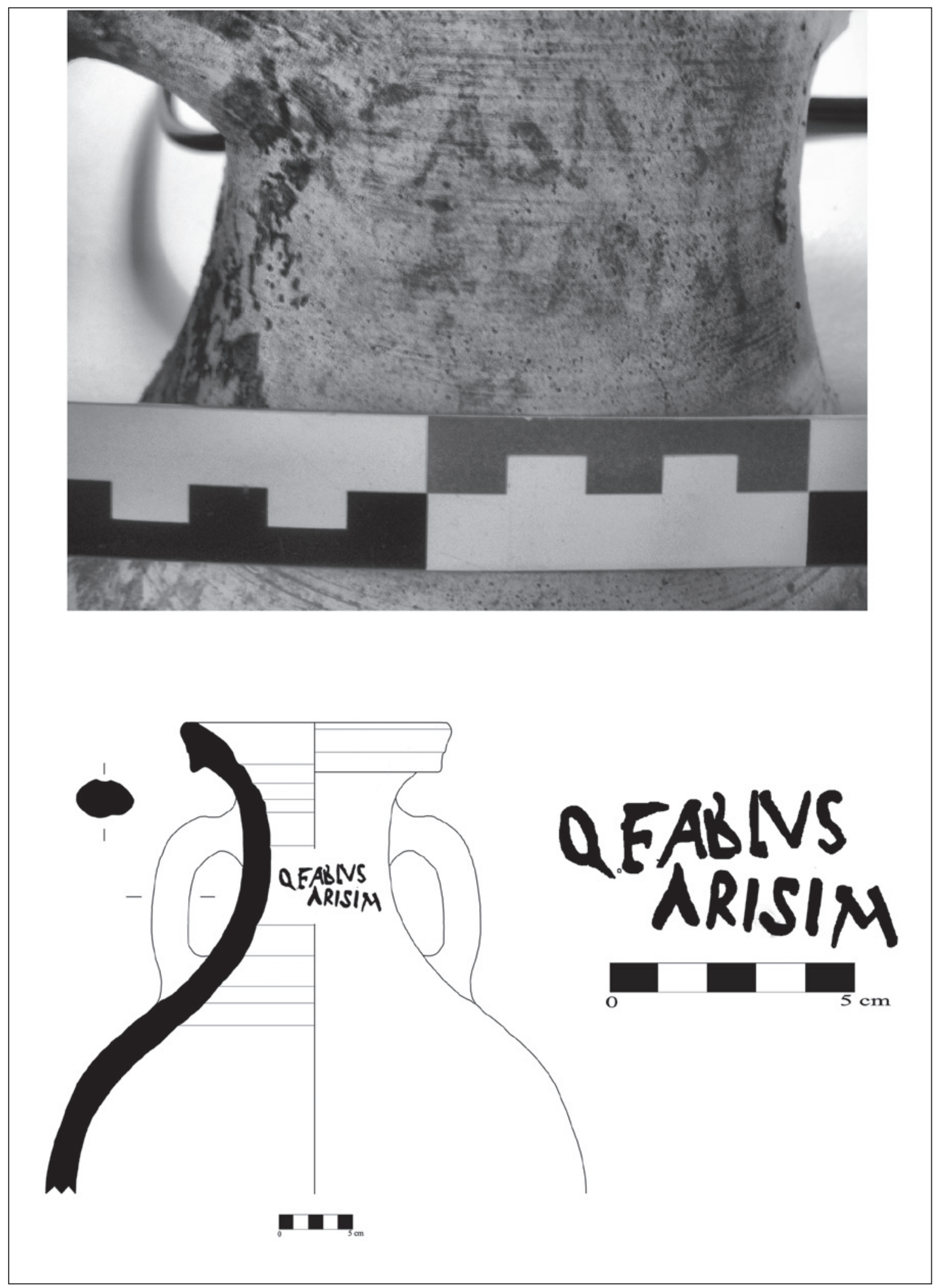

Figura 3. Fotografía y dibujo del titulus pictus. 


\section{EL PROBLEMA DE LOS TITULI PICTI, UBICACIÓN E INTERPRETACIÓN}

Desde los pioneros trabajos de Dressel (1878), ha sido un claro objetivo de los investigadores tratar de sistematizar una estructura normativa que facilitara la comprensión de la información proporcionada por los tituli picti. El propio Dressel, tras el estudio de un importante conjunto de ánforas depositadas en Roma -en concreto de Castro Pretorio y, sobre todo, del monte Testaccio-, realizó una propuesta para las ánforas de aceite béticas encuadradas en el $\mathrm{n}^{\circ} 20$ de su tabla tipológica del CIL XV, pero evitó proponer otra para los epígrafes procedentes de ánforas vinarias o de salazones, debido a la menor cantidad de tituli picti conocidos y a su gran variedad (Aguilera 2004: 120-122). La nomenclatura empleada por Dressel se sigue empleando en la actualidad, si bien ha ido variando el significado que se da a algunos de los registros.

El titulus pictus que presentamos puede relacionarse con el elemento $\beta$ usado para las ánforas olearias, nomenclatura que ha sido utilizada por algunos investigadores también para las ánforas de salazones (Colls et al. 1977). En ambas clases de ánfora, la presencia de trianomina in collo se vincula con el ámbito de comercialización del producto, sin que haya un consenso en torno a si se refiere al mercator, negotiator o al navicularius encargado del transporte del mismo (Remesal 2000) y, además, no siempre se observa con claridad la distinción entre estos agentes comerciales (Martínez 2007).

En relación con las ánforas Ovoides gaditanas, no hemos encontrado ningún otro titulus pictus, ausencia que probablemente puede ser debida a que fuese una práctica poco extendida en ese tipo -y en general en las ovoides producidas en el I a.C. en Hispania Ulterior, sin que deba sustraerse como causa el relativo escaso número de ejemplares identificados. Por ello, el referente más cercano lo encontramos en las ánforas Dressel 9 y 10, derivadas de la Ovoide gaditana, en las que diversos tituli picti -fechados en la primera mitad del I d.C.- presentan trianomina en posición $\beta$ atribuidos a mercatores y que preferentemente vienen en genitivo (Étienne y Mayet 1998, Lagóstena 2004).

\section{QUINTUS FABIUS ARISIM: EL PERSONAJE}

En resumen, el titulus pictus que presentamos nos remite a un ciudadano romano de origen púnico que se dedicaría al comercio de larga distancia, probablemente de salazones obtenidas de la industria pesquero-conservera de la bahía de Cádiz. El origen púnico del cognomen Arisim permite relacionarlo con la integración de las estructuras y de los agentes comerciales púnicos en la dinámica comercial romana, en un proceso iniciado tras el fin de la Segunda Guerra Púnica (218-201 a.C.). El pacto entre Roma y Gades permite intuir la buena predisposición con la que las clases dirigentes gaditanas acogieron la llegada de Roma (López 1991, 1995). Las actividades comerciales del sur hispano no parecen resentirse (García 2004b: 110), pues las oligarquías púnicas aprovecharon las oportunidades que el monopolio del control del Mediterráneo por parte de la potencia itálica ofrecía para el comercio (Ramón 2008: 87). A modo de ejemplo, las ánforas de salazones púnicas se encuentran en gran número en los campamentos romanos, asociadas a ánforas itálicas desde fechas tempranas, tal y como sucede con las T-9.1.1.1. en el paradigmático caso de los campamentos militares numantinos (Sanmartí 1985a-b).

Asimismo, el impulso dado en las últimas décadas al conocimiento sobre los alfares y las factorías de salazones del sur de Hispania permite constatar una clara continuación de la tradición anterior en estas estructuras y el mantenimiento durante el siglo II a.C. y gran parte del I a.C. de producciones anfóricas de morfología púnica, así como la pervivencia de la epigrafía del mismo origen (Ramón 1995, Lagóstena 2001, 2004, Sáez 2008), lo que permite descartar que se originase una alteración abrupta de la economía púnica, ni de las estructuras en las que ésta se apoyaba.

\section{CONCLUSIÓN}

El mundo púnico surhispano, con Gades a la cabeza, se abre a los nuevos mercados que surgirían a raíz de su inclusión en la órbita romana, sin abandonar sus antiguos circuitos comerciales. El titulus pictus expuesto nos lleva a pensar que a finales de la época tardorrepublicana no existía un monopolio de los comerciantes itálicos, sino que los de origen púnico conservarían parte de su anterior protagonismo, al menos respecto a las rutas tradicionales de lo que Morel denominó "aire punicisante" (1983), de la que formarían parte las antiguas colonias fenicias de la costa almeriense. Fue una práctica habitual del imperialismo romano apoyarse en las oligarquías políticas y económicas de las poblaciones conquistadas para facilitar su control y el aprovechamiento económico de los territorios, en unas relaciones de las que ambas partes salían claramente beneficiadas, pues permitían 

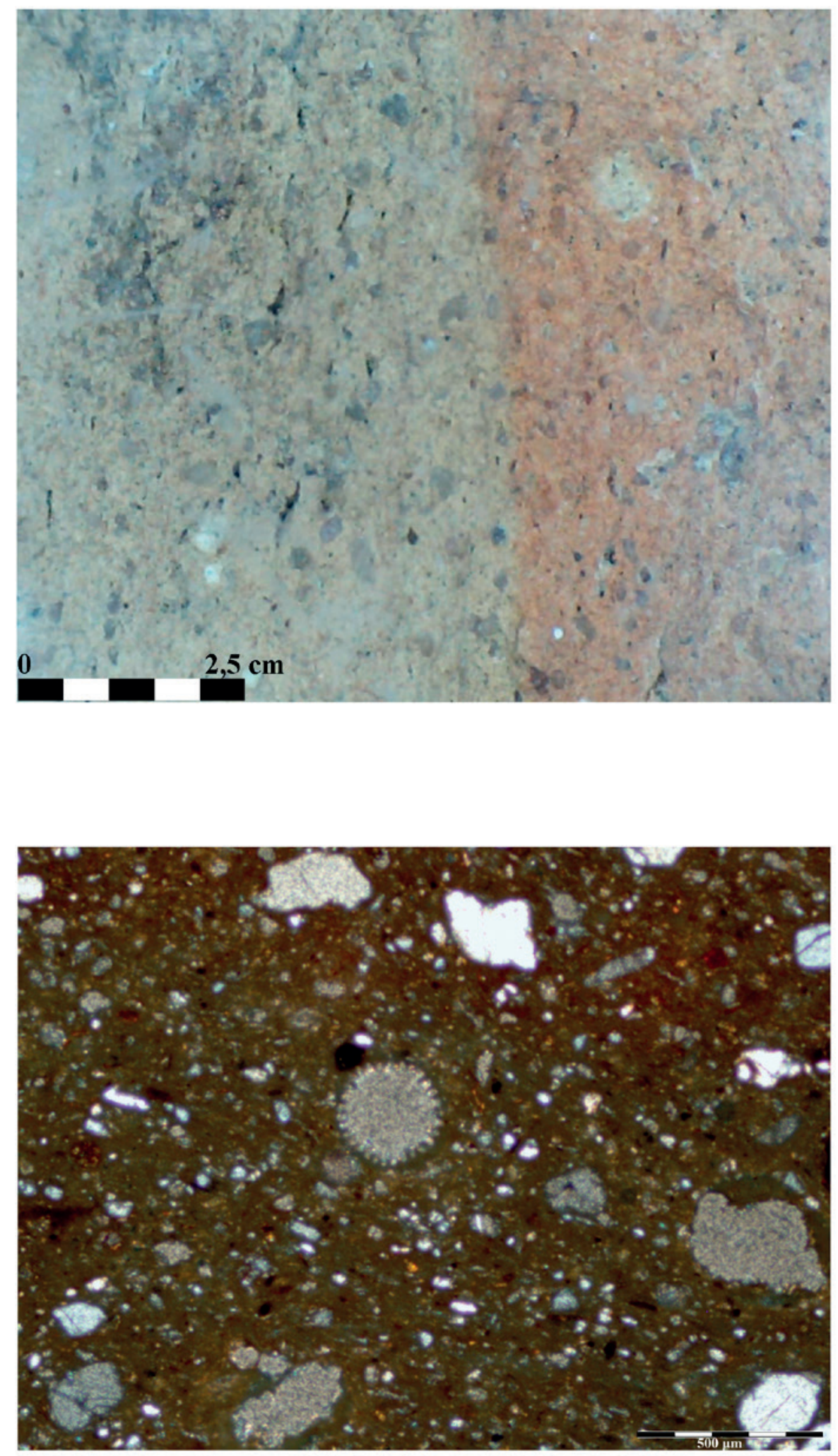

Figura 4. Fotografía con microscopio digital (15X) y lámina delgada (40X).

ISSN: 1133-4525 ISSN-e: 2255-3924 


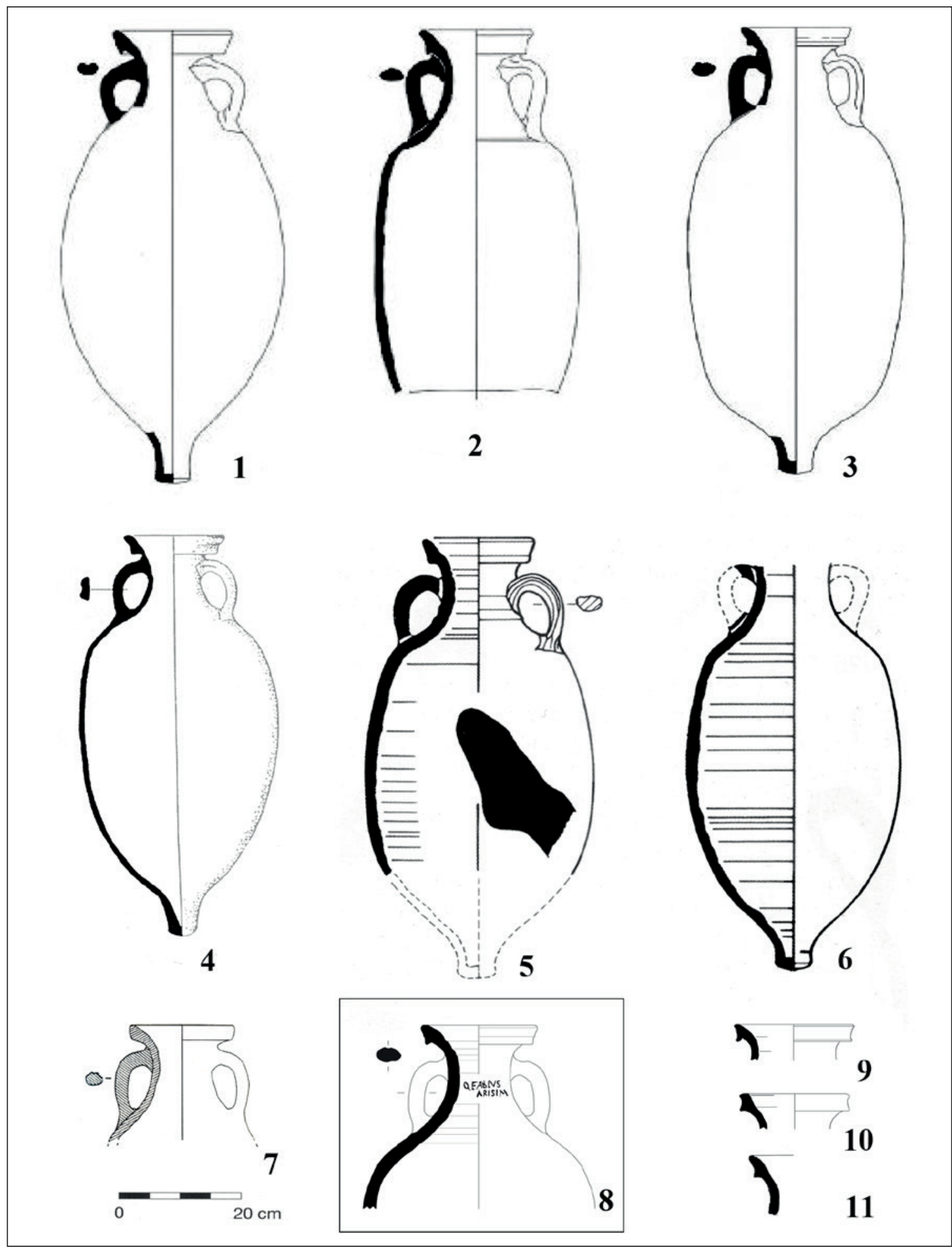

Figura 5. Lámina comparativa de ánforas Ovoides gaditanas: 1-2. Illes Formigues (Martín 2008), 3. Cala Bona I (Martín 2008), 4. Grand Conglué 3 (Liou 2001: 1102, fig J), 5-6. Castelo de Lousa (Morais 2010: 201, fig 28: 14-15), 7. Vejer de la Frontera (García 1998: 351, fig 33:2), 8. Villaricos (ejemplar presentado en este trabajo), 9-10. El Rabatún (García y López 2008: 297, fig. 11:5 y 17), 11. Cádiz (Niveau de Villedary y Blanco 2007: 216, Fig. 10:4). 
a las oligarquías indígenas conservar su poder y estatus anterior a la conquista (López 2004: 65-66). En el tercer cuarto del I a.C., la integración dentro del ámbito romano está bastante avanzada y los comerciantes púnicos continuarían con su actividad tradicional integrándose dentro de las redes clientelares de las oligarquías itálicas.

En definitiva, muchas son las incógnitas que se ciernen sobre los procesos de integración entre la población autóctona del sur de la Península Ibérica y los conquistadores itálicos. Consideramos que deben desterrarse planteamientos extremos que otorguen todo el peso de la actividad económica a las oligarquías itálicas, al igual que tampoco nos parece asumible plantear una perduración de la economía púnica sin apenas cambios hasta época augustea. Creemos pues, que la integración entre ambos sectores debe entenderse dentro de planteamientos más complejos y, bajo esta perspectiva, la epigrafía anfórica se muestra como un instrumento desde el que poder lanzar nuevas hipótesis que nos permitan aproximarnos a estos procesos. El titulus pictus que presentamos es buena prueba de ello.

\section{AGRADECIMIENTOS}

El presente trabajo se inserta en el proyecto " $\mathrm{Am}$ phorae ex Hispania: paisajes de producción y consumo" (HAR2011-28244). El estudio de los materiales depositados en el Museo Arqueológico Provincial de Almería procedentes de la excavación del sector 8 de Villaricos se realizó gracias al permiso concedido por la Delegación Provincial en Almería de la Consejería de Cultura de la Junta de Andalucía. Agradecemos asimismo al Dr. E. García Vargas y a R. R. Almeida sus valoraciones sobre la adscripción tipológica y las características ceramológicas de la pieza.

\section{BIBLIOGRAFÍA}

Abascal Palazón, J.M. (1994): Los nombres personales en las inscripciones latinas de Hispania. Murcia, Universidad de Murcia.

Aguilera Martín, A. (2004): "Sistematización de los $t i$ tuli picti anfóricos para la base de datos CEIPAC", en J. Remesal (ed.), Epigrafía anfórica. Col.Instrumenta 17, pp. 105-126. Barcelona, Universitat de Barcelona.

Almagro Gorbea, M.J. (1984): La necrópolis de Baria (Almería). Campañas de 1975-78. Ministerio de
Cultura, Dirección General de Bellas Artes y Archivos, Madrid.

Almagro Gorbea, M.J. (1986): "Las ánforas de la antigua Baria (Villaricos)", en G. del Olmo, M. E. Aubet (eds.), Los fenicios en la Península Ibérica, vol. II, pp. 265-283. Sabadell, Ausa.

Almagro Gorbea, M.J. (1991): "La alimentación en la antigua Baria en época romana y prerromana", en Alimenta, estudios en homenaje al Dr. Michel Ponsich. Anejos de Gerión 3, pp. 119-128. Madrid, Universidad Complutense.

Almeida, R.R. (2008): Las ánforas del Guadalquivir en Scallabis (Santarém, Portugal), una aportación al conocimiento de los tipos minoritarios. Col. Instrumenta 28. Barcelona, Universitat de Barcelona.

Aranegui, C. (2002): "Las ánforas con la marca $M A \Gamma O N$ ", en L. Rivet y M. Sciallano (eds.), Vivre, produire et échanger: reflets méditerranéens. Mélanges offerts a B. Liou, pp. 409-415. Montagnac, Monique Mergoil.

Benquet, L. y Olmer, F. (2002): "Les amphores", en J.M. Blázquez Martínez, C. Domergue y P. Sillières (eds.), La Loba (Fuenteobejuna, province de Cordoue, Espagne). La mine et le village minier antiques, pp. 295-331. Bordeaux, Ausonius.

Canto, A.M. (1978): "Una familia bética: Los Fabii Fabiani". Habis 9: 293-310.

Cara Barrionuevo, L. (2007): "El material arqueológico de las excavaciones en el Sector 8 de Villaricos (Almería). Mil años de historia de una ciudad mediterránea occidental en la Antigüedad", en Actas de las Jornadas sobre la Zona Arqueológica de Villaricos, pp. 89-130. Almería (2005), Sevilla, Conserjería de Cultura de la Junta de Andalucía.

Chic García, G. (1980): “Acerca de un ánfora con pepitas de uvas encontrada en la Punta de la Nao (Cádiz)". Boletín del Museo de Cádiz I: 37-41.

Chic García, G. (2003): "Nuevos datos económicos sobre el senador hispalense Fabius Iulianus", en Vrbs Aeterna. Coloquio Internacional Roma entre la Literatura y la Historia, pp. 381-396. Pamplona, Universidad de Navarra.

Colls, D., Étienne, R., Léquement, R., Liou, B. y Mayet F. (1977): “L' épave Port-Vendres II et le commerce de bétique à l'époque de Claude". Archaeonautica 1. Paris.

Dressel, H., (1878): "Ricerche sul monte Testaccio". Annali dell'Istituto di Correspondenza Archeologica 50: 118-192

Étienne, R. y Mayet, F. (1998): "Les mercatores de saumure hispanique". Mélanges de l'École française de Rome 110: 147-165. 
Étienne, R. y Mayet, F. (2000): Trois clés pour l'économie de l'Hispanie romaine. I- Le vin hispanique. París, De Boccard.

Fabião, C. (1989): Sobre as ânforas do acampamento romano da Lomba do Canho (Arganil). Cadernos da UNIARQ 1. Lisboa, Instituto Nacional de Investigação Científica.

Fabião, C. (2001): "Sobre as mais antigas ânforas romanas da Baetica no Ocidente Peninsular", en Ex Baetica Amphorae. Conservas, aceite y vino de la Bética en el Imperio Romano, pp. 665-682. Écija (1998), Écija, Gráficas Sol.

García Vargas, E. (1996): “La Producción anfórica en la Bahía de Cádiz durante la República como índice de romanización". Habis 27: 49-62.

García Vargas, E. (1998): La producción de ánforas en la Bahía de Cádiz en época romana (ss. II a.C. - IV d.C.). Écija (1998), Écija, Gráficas Sol.

García Vargas, E. (2004a): "El vino de la Bética altoimperial y las ánforas. A propósito de algunas novedades epigráficas". Gallaecia 24: 117-134.

García Vargas, E. (2004b) "La Romanización de la industria púnica de las salazones en el sur de Hispania”, en XVI Encuentros de Historia y Arqueología, pp. 101129. San Fernando, Cádiz (2000), Córdoba, Cajasur.

García Vargas, E. (2010): “Ánforas béticas de época augusteo-tiberiana. Una retrospectiva", en A.M. Niveay de Villedary (coord.), Las necrópolis de Cádiz: apuntes de arqueología gaditana en homenaje a J.F. Sibón Olano, pp. 581-624. Cádiz, Universidad de Cádiz.

García Vargas, E.y López Rosendo, E. (2008): "El alfar de Rabatún (Jerez de la Frontera, Cádiz) y la producción de ánforas y cerámica común en la campiña del Guadalete en época altoimperial romana". Spal 17: 281-313. http://dx.doi.org/10.12795/spal.2008. i17.12

García Vargas, E. y Bernal Casasola, D. (2008): “Ánforas de la Bética”, en D. Bernal Casasola, D. y A. Ribera i Lacomba, A. (eds.), Cerámicas hispanorromanas: un estado de la cuestión: 661-687. Cádiz, Universidad de Cádiz.

García Vargas, E.; Almeida, R.R. y González Cesteros, H. (2011): "Los tipos anfóricos del Guadalquivir en el marco de los envases hispanos del siglo I a.C. Un universo heterogéneo entre la imitación y la estandarización”. Spal 20: 185-283. http://dx.doi. org/10.12795/spal.2011.i20.12

González Fernández, J. (1989): Corpus de inscripciones latinas de Andalucía, vol. II, tomo 1. Sevilla, Junta de Andalucía.
Jongeling, K. (1984): Names in Neo-Punic Inscriptions. Groningen, Rijksuniversiteit te Groningen.

Jongeling, K. (1994): North-African names from latin sources. Research School. Leyden, CNWS Publications.

Lagóstena Barrios, L. (2004): "Las ánforas salsarias de Baetica. Consideraciones sobre sus elementos epigráficos", en J. Remesal (ed.), Epigrafía anfórica. Col. Instrumenta 17, pp. 197-220. Barcelona, Universitat de Barcelona.

Liou, B. (2001): “Las ánforas béticas en el mar. Les épaves en Méditerranée à cargaison d'amphores de Bétique", en Ex Baetica Amphorae. Conservas, aceite y vino de la Bética en el Imperio Romano, pp.1061-1110. Écija (1998), Écija, Gráficas Sol.

López Castro, J.L. (1991): "El foedus de Gadir del 206 a.C.: Una revisión". Florentia Iliberritana 2: 269-280.

López Castro, J.L. (1995): Hispania Poena: los fenicios en la Hispania romana. Barcelona, Crítica.

López Castro, J.L. (2007): "La ciudad fenicia de Baria. Investigaciones 1987-2003”, en Actas de las Jornadas sobre la Zona Arqueológica de Villaricos, pp. 19-39. Almería (2005), Sevilla, Junta de Andalucía.

López Medina, M.J. (2004): Ciudad y territorio en el sureste peninsular durante época romana. Madrid, Ediciones Clásicas.

Madoz, P. (1846): Diccionario Geográfico-EstadísticoHistórico de España y sus posesiones de ultramar. Madrid, Establecimiento tipográfico de P. Madoz y L. Sagasti.

Martín Menéndez, A. (2008): “Àmfores tarraconenses $\mathrm{i}$ bètiques en els derelictes de mitjan segle I a.C. a la costa catalana", en Actes du congrès de l'EscalaEmpúries. Les productions céramiques en Hispanie Tarraconaise (IIe siècle avant J.-C VIe siècle après J.-C). Actualité des recherches céramiques, pp.103127. Marsella, Societé Française d'Etude de la Céramique Antique en Gaule

Martínez Maganto, J. (2007): “Una inscripción inédita de Pecio Gandolfo. El complejo análisis de los $t i$ tuli picti en ánforas salsarias y el comercio de salsamenta", en L. Lagóstena, D. Bernal y A. Arévalo (eds.), Cetariae 2005: salsas y salazones de pescado en occidente en la Antigüedad. Actas del Congreso Internacional. BAR International Series 1686, pp. 391-400. Cádiz (2005), Oxford, Hadrian Books.

Mateo Corredor, D. (2012): "La importación de aceite tripolitano en Hispania Ulterior durante la época tardorrepublicana”, en A. Castro, D. Gómez, G. González, K. Starczewska, J. Oller, A. Puy, R. Rieraand 
N. Villagra (eds.), Estudiar el pasado: aspectos metodológicos de la investigación en Ciencias de la Antigüedad y de la Edad Media. BAR International Series 2412, pp. 119-127. Oxford, Hadrian Books.

Molina Vidal, J. (2001): "Las primeras exportaciones béticas en el Mediterráneo occidental", en Ex Baetica Amphorae. Conservas, aceite y vino de la Bética en el Imperio Romano, pp. 637-645. Écija (1998), Écija, Gráficas Sol.

Molina Vidal, J. (2007): “Commerce romain et amphores nordafricaines sur la côte sud orientale d'Hispanie", en A. Mrabet, J. Remesal (eds.), Africa et in Hispania: Etudes sur l'huile africaine. Col. Instrumenta 25, pp. 205-243. Barcelona, Universitat de Barcelona.

Morais, R. (2010): “Ânforas”, en J. Alarcao, P.C. Carvalho y A. Gonçalves (coords.), Castelo da LousaIntervenções Arqueológicas de 1997 a 2002. Studia Lusitana 5: 181-218.

Morales Sánchez, R. (2007): “Urbanismo y evolución urbana en la ciudad púnico-romana de Villaricos (Cuevas de Almanzora, Almería): Baria a partir de las excavaciones de 2004", en Actas de las Jornadas sobre la Zona Arqueológica de Villaricos, pp. 41-88. Almería (2005), Sevilla, Junta de Andalucía.

Morel, J. (1983): "La céramique à vernis noir de Carthage-Byrsa: nouvelles données et élements de comparaison", en Actes du Colloque sur la céramique antique. Dossier CEDAC 1, pp. 43-76. Cartago (1980), Cartago, Centre d'Etudes et de Documentation Archéologique de Carthage.

Niveau de Villedary y Mariñas, A.M. y Blanco Jiménez, F. J. (2007): "Continuidad púnica en la Gades republicana. La producción vascular del horno de la calle Troilo". Spal 16: 195-224. http://dx.doi. org/10.12795/spal.2007.i16.10

Perdigones Moreno, L.; Muñoz Vicente, A.; Gordillo Acosta, A. y Blanco Jiménez, F.J. (1986):
"Excavaciones de urgencia en un solar de la plaza de San Severiano, esquina c/Juan Ramón Jiménez (Chalet Varela, Cádiz)". Anuario Arqueológico de Andalucía, 1986, t. III: 50-54.

Ramón Torres, J. (1995): Las ánforas fenicio-púnicas del Mediterráneo central y occidental. Col. Instrumenta 2. Barcelona, Universitat de Barcelona.

Ramón Torres, J. (2008): "El comercio púnico en occidente en época tardorrepublicana (siglos -II/-I): Una perspectiva actual según el tráfico de productos envasados en ánforas", en J. Uroz Sáez; J.M. Noguera y F. Coarelli (coords.), Iberia e Italia: modelos romanos de integración territorial, pp. 67-100. Murcia, Tabularium.

Remesal Rodríguez, J. (2000): “L. Marius Phoebus mercator olei hispani ex provincia Baetica. Consideraciones en torno a los términos mercator, negotiator y difussor olearius ex Baetica", en G. Paci (ed.), Epigraphai. Miscellania epigrafica in onore di Lidio Gasperini, pp. 781-797. Roma, Tipigraf.

Sáez Romero, A.M. (2008): La producción cerámica en Gadir en época tardopúnica (siglos III/-I). BAR International Series 1812. Oxford, John and Erica Hedges.

Sanmartí Greco, E. (1985a): “Las ánforas romanas del campamento numantino de Peña Redonda (Garray, Soria)". Empúries 47:130-161.

Sanmartí Greco, E. (1985b): "Sobre un nuevo tipo de ánfora de época republicana de origen presumiblemente hispánico", en Ceràmiques gregues $i$ hel. lenístiques a la Península Ibèrica. Taula rodona amb motiu del $75^{\circ}$ aniversari de les excavacions d'Empúries, pp. 133-141. Ampurias (1983), Barcelona, Diputación de Barcelona.

Siret, L. (1906): Villaricos y Herrerías. Antigüedades púnicas, romanas, visigóticas y árabes. Madrid, Real Academia de la Historia. 